\title{
«VUESTRA OLIVA ES LAUREL DE MI CABEZA»: LOPE DE VEGA Y LA BÚSQUEDA DEL PARNASO ÁULICO
}

\author{
Francisco Florit Durán \\ Universidad de Murcia
}

\section{Resumen}

En el presente artículo analizo las estrategias literarias lisonjeras desplegadas por el último Lope con el propósito de acercarse a las esferas del poder, a los posibles mecenas. Me interesa, sobre todo, dar cuenta de la intrahistoria de algunos de los poemas escritos por Lope en sus últimos años, las circunstancias en las que se escribieron, sus destinatarios o con qué ocasión fueron elaborados. Ofrecemos, pues, una selección de poemas —algunos muy poco conocidos— que, en nuestra opinión, servirá para ver cómo debemos tomar con cierta prevención las reiteradas lamentaciones del Fénix acerca de la falta de apoyo y aprecio por parte de la órbita de los poderosos, especialmente, de Felipe IV y del conde-duque de Olivares.

Palabras clave: Lope último, mecenazgo, poesía áulica, Conde-duque de Olivares.

\section{«YOUR OLIVE IS THE LAUREL OF MY HEAD»: LOPE DE VEGA AND THE SEARCH FOR AULIC PARNASSUS}

\begin{abstract}
The present article aims to deal with the flattering literary strategies deployed in the last works of Lope with the purpose of approaching the spheres of power, that is, his possible patrons. I am interested, above all, in giving an account of the intra-history of some of the poems written by Lope in his last years, the circumstances in which they were written, their intended audience and the purpose they were elaborated for. Therefore the intention of this article is to offer a set of poems - some of them, very little known-, that, in our opinion, will show how we should take with some prevention the reiterated lamentations of the so-called «Phoenix of Wits» about the lack of support and appreciation from the orbit of the powerful, especially from Philip IV and the Count-Duke of Olivares.

Keywords: Last Lope, Patronage, Aulic Poetry, Count-Duke of Olivares.
\end{abstract}


No son pocos los escritores de la literatura universal que experimentaron en sus propias carnes el aforismo Carmina non dant panem o los que confesaron más o menos abiertamente ser poetas de pane lucrando, tal y como decía Lope de sí mismo en la conocida y citada carta al conde Lemos del 6 de mayo de $1620^{1}$.

Para ganarse el sustento buena parte de los escritores tuvieron que recurrir a los mecenas, a los autores de comedias o directores de la compañía teatrales, a los mercaderes de libros y al público. De manera que cabe hablar en el panorama del Siglo de Oro español de escritores-aristócratas, escritores-secretarios/criados y escritores-profesionales. Lo verdaderamente interesante es el hecho de que en nuestro Siglo de Oro podemos observar cómo hubo escritores que recurrieron a casi toda la escala de modalidades de sustento y, ligado a ello, y no menos importante, al empleo de las estrategias y de las modalidades genéricas a ellas vinculadas. De lo que se trata aquí, por consiguiente, es de situarnos en la llamada cultura del mecenazgo, en su sistema económico y en las retóricas de la fidelidad y del servicio, por medio de las cuales el escritor y su patrón establecen un haz de relaciones en las que en no pocas ocasiones aquel se ve obligado a ofrecer, precisamente, sostenidas muestras de adulación, de fidelidad, de servicio y de entrega con la esperanza incierta de obtener unos resultados que suelen ser frustrantes para el autor de la obra, encaminándolo a buscar otros señores, otros patrones, en suma, otros mecenas. Pues, y cito otro aforismo latino, Necessitas caret lege. Creo que viene bien aquí traer las famosas palabras de Lope que están en una carta al duque de Sessa fechada el 17-18 de mayo de 1620:

Dirá Vex. a: «QQué ocupaciones estas de un hombre de bien!», y responderé yo que no puedo más: que como la naturaleza hizo un cojo, un tuerto y un corcovado, hizo un pobre, un desdichado y un poeta, que en España son como rameras: que todos querrían echarse con ellas, pero por poco precio y, en saliendo de su casa, llamarlas putas (Vega, 1989: IV 55).

Como quiera que sea, de lo que deseo ocuparme ahora es de las estrategias literarias lisonjeras desplegadas por el último Lope de Vega para acercarse a las esferas del poder y, a su vez, de la construcción de una serie lírica de marcado carácter reivindicativo; ya que, como muy bien apunta García Reidy (2013: 214), «la biografía de Lope es la de un literato que estuvo vinculado durante toda su vida a la nobleza, en la que buscó protectores que le

1 El fragmento que nos interesa dice así: «Yo he estado un año sin ser poeta de pane lucrando: milagro del señor Duque de Osuna, que me envió quinientos escudos desde Nápoles, que, ayudados de mi beneficio, pusieron la olla a estos muchachos, entre los cuales hay quince años de una doncella, virtuosos y no sin gracias» (Vega, 1989: IV 54). 
ayudaran a medrar en los círculos cortesanos y le permitieran alcanzar sus aspiraciones de disfrutar de un mecenazgo regio».

Como es bien sabido, fue el profesor Juan Manuel Rozas (1990: 73-131) el que acuñó la expresión «ciclo de senectute» para referirse al último periodo de la producción del Fénix, los años que abarcan de 1627 a 1635, periodo marcado por la decadencia física, por los apuros económicos y por las desgracias familiares ${ }^{2}$. Se ha dicho siempre que los intentos de acercarse al nuevo poder encarnado por Felipe IV y por Olivares nunca llegaron a tener los resultados apetecidos — aunque esto algo que más adelante matizaré-, y Lope va lentamente sumiéndose en el desengaño y la melancolía. A este respecto señalaba Felipe Pedraza en uno de sus primeros trabajos sobre el Fénix:

A los setenta y dos años Lope debía de estar muy harto de los Austrias y de la nobleza en general, aunque seguía dependiendo de las dádivas de don Luis Fernández de Córdoba. Las Rimas de Tomé de Burguillos son un desahogo contra el olvido en que se le tiene. La temática burlesca queda justificada por el convencimiento del poeta de que no merece la pena cantar glorias militares - tan escasas ya en 1634- ni escribir alabanzas que nadie va a agradecer ni pagar³.

Por cierto, en una carta de fines de 1632 dirigida a un poeta desconocido, Lope dice lo siguiente: «Que a fe que no estoy para gracias, viendo después de dos años la poca que he merecido en tan justa pretensión con tantos servicios. Pecados míos son, Dios los castiga, paciencia» (Vega, 1989: IV 150). Recuérdese, a este propósito, que por la misma época, finales de 1632 o principios de 1633, dejó escrito estos versos dirigidos a su propio Huerto deshecho (Vega, 2015: II 117):

Consuélate conmigo, que, después de dos años pretendiente, los servicios no digo, que fuera memorial impertinente: basta que sepas tú que me pareces, pues que te pierdes más cuanto más creces.

El propio Rozas (1990: 75) cita la conocida y tantas veces citada carta al duque de Sessa en la que Lope manifiesta su deseo de dejar el teatro, entre otros motivos porque el público ya no es tan receptivo a sus creaciones:

2 Para la trayectoria biográfica de Lope de Vega sigue siendo muy útil Rennert y Castro (1969). Puede consultarse con provecho Pedraza Jiménez (2008a y 2008b). Asimismo, es muy recomendable la reciente biografía de Lope escrita por Sánchez Jiménez (2018).

3 Pedraza Jiménez (1978: 398); también puede leerse el artículo en (2008a: 159-197). 
Días ha que he deseado dejar de escribir para el teatro, así por la edad, que pide cosas más severas, como por el cansancio y aflicción de espíritu en que me ponen... Ahora, señor excelentísimo, que con desagradar al pueblo dos historias que le di bien escritas y mal escuchadas, he conocido, o que quieren verdes años, o que no quiere el cielo que halle la muerte a un sacerdote escribiendo lacayos de comedias, he propuesto dejarlas de todo punto, por no ser como las mujeres hermosas, que a la vejez todos se burlan de ellas... ${ }^{4}$

Por cierto, que estas palabras de Lope guardan no poca relación con las que Tirso de Molina dejó escritas más o menos por esos años en su miscelánea Deleitar aprovechando:

Buscaba, pues mi pluma, alguna disposición nueva, que la medrase crédito con tales tres asuntos. Tal vez imaginaba fiarlos al teatro en otras tres comedias, pero apenas me las consultaba el pensamiento, cuando, retrocediendo, él mismo me advertía cuan desganado el auditorio a todo lo sagrado. Amenazaba atrevimientos, ya envidiosos ya ignorantes, si los unos de los otros se distinguen, lo contingente del aplauso; lo peligroso de las ostentaciones carpinteras y pintoras, adonde han dado en acogerse, como a portería de convento, las penurias de las trazas y sentencias; la poca fe que ganan las verdades con los ensanches mentirosos que en semejantes argumentos añaden la musas, pues no hay comedia de las de esta especie en que no pongan más prodigios de su casa que encierra un Flos Sanctorum, como les venga a cuenta las tramoyas, sin que escrupulicen los poetas las censuras que el concilio sacrosanto tridentino fulmina contra los que fingen milagros nunca sucedidos; y últimamente recelaba el saber por experiencia lo poco que permanece la memoria de los varones célebres que por este camino se manifiestan al concurso, pues la que más goza, es en la corte quince días, y en los demás pueblos tres o cuatro, quedando al tercer año sepultados sus cuadernos en los legajos, cuando mucho, de algún tratante papelista ${ }^{5}$.

Creo que, a este respecto, viene bien recoger aquí unos versos, probablemente se trate de un fragmento de un texto poético que iba a ser más largo, que están en el códice Daza, es decir, en el último de los cuadernos de trabajo de Lope, y que no son muy conocidos por no figurar entre las obras impresas del autor. Dicen así:

4 Vega (1989: IV 144). Amezúa data conjeturalmente esta carta (n. ${ }^{\circ}$ 524) en «Madrid, ¿mediados o fines de 1630?». Rennert y Castro (1969: 287-288) adelantan la fecha a 1629. Pérez de Montalbán (2001: 30) señala: «trescientos [ducados)] de una prestamera que le dio en un lugar suyo el excelentísimo señor duque de Sessa, su amigo, su valedor, su dueño y su heroico mecenas, y más, cuatrocientos ducados para su plato de muchos años a esta parte, porque le dijo que no quería escribir más comedias».

5 Florit Durán (1986: 120). Recojo este texto y otros parecidos en Florit Durán (1986). 
Pregúntasme, don Luis, si harás comedias

con estas cuatro escenas que me envías, heroicas en estilo de tragedias.

De mi censura dices que confías y que proseguirás si las apruebo. ¿Por qué te humillas a imitar las mías?

Mejor a entrambos nos ayude Febo que te aconseje yo que a tales musas muevas la pluma con aliento nuevo.

Altas materias te darán difusas cuando pretendas conquistar la fama: cuanto de más valor menos confusas. Aquel ingenio que laureles ama no los busque en el vulgo: atento aspire a más ilustre rama ${ }^{6}$.

Obsérvese que el fragmento conservado consta de 15 versos, estructurados en tercetos encadenados ABA-BCB-CDC-DED-EFE. Tiene toda la pinta de tratarse de un fragmento de una epístola dirigida a un tal don Luis. El contenido es metaliterario, pues Lope, ante la petición de don Luis — «Pregúntasme, don Luis, si harás comedias»—, desgrana algunos consejos sobre su manera de entender el teatro. Pero, por estas fechas, estamos ya ante un Lope entre desengañado y un tanto burlón, de ahí que le aconseje a don Luis que busque los «laureles», es decir, el reconocimiento de los entendidos no en el vulgo, sino en un tipo de literatura de más altos vuelos: «Atento (se refiere a don Luis) aspire a más ilustre rama».

Ya que he citado el códice Daza, quiero hacer un pequeño paréntesis para destacar que la existencia de tres códices autógrafos de Lope de Vega, de tres cuadernos de trabajo, de la última etapa de su vida (los llamados Durán, Pidal y Daza, denominados así por sus antiguos poseedores) aporta a los estudiosos de la obra del escritor madrileño un rico conjunto de textos que hay que desentrañar con cuidado para ver qué importancia tienen en lo que se refiere al Lope último. Téngase muy en cuenta que estos códices autógrafos del Fénix conservan todavía no pocos inéditos, y nos dan la clave para encontrar también un buen número de poesías (algunas desconocidas del todo, otras nunca publicadas), algunas de las cuales son con toda seguridad textos dramáticos (loas, bailes) que se creían hoy perdidos, pero que simplemente hay que ubicar en la comedia a la que corresponden.

El códice Durán, así llamado por haber pertenecido a don Agustín Durán, es hoy propiedad de la familia Masaveu. Recoge textos escritos por

${ }^{6}$ Entrambasaguas (1970: 109-110). En el Códice Daza figura en los fols. 33r-33v del reverso. 
Lope entre finales de 1628 y los últimos meses de 1629 y ha sido publicado en una cuidada edición a cargo de Víctor García de la Concha y Abraham Madroñal Durán (Vega, 2011). El códice Pidal, que perteneció a don Pedro José Pidal, primer Marqués de Pidal, y que hoy lo poseen sus herederos, consta de 107 folios y tiene 58 composiciones, la mayoría de ellas inéditas. Por su parte, el Daza es un volumen en 4..$^{\circ}$ formado por 200 hojas en el anverso y 48 en el reverso, de las cuales son útiles 211 y el resto en blanco. Es un volumen facticio, en papel verjurado, que contiene composiciones de Lope escritas entre agosto de 1631 y, probablemente, ese mismo mes de 1635. Se encuentran en dicho códice un buen número de composiciones inéditas hasta ese momento y otras que pertenecen a libros de Lope como las Rimas de Burguillos y La Dorotea, especialmente, aparte de otros en menor medida. Incorpora algunas obras completas como Huerto deshecho (1633) o la Elegía a Villaizán (1633), también alguna declaración en prosa como la que prestó Lope en el proceso de beatificación del hermano Bernardino de Obregón. Fue editado en parte por Joaquín de Entrambasaguas (1970) en Revista de Literatura, con no pocos errores en la transcripción de los poemas. El sistema que siguió fue reproducir en foto algunos folios, pero transcribió tan solo aquellas composiciones que consideraba inéditas, limitándose a dar el primer y último verso de aquellas otras ya editadas, de las que señalaba la edición y, en todo caso, las divergencias del manuscrito que trataba. Hoy en día es propiedad de la Biblioteca Nacional de España (Vega, 1631-1634).

Como quiera que sea, ¿qué se esconde detrás de esas cartas o de esas poesías? Algo tan fácil de explicar como el hecho de que a Lope y a los demás dramaturgos se les había cerrado una importante fuente de ingresos. Desde 1625 el consejo de Castilla decidió no otorgar nuevos permisos para la impresión de comedias o novelas 7 . Como recuerda Pedraza Jiménez (2003: 196):

Sabemos que esta prohibición disgustó profundamente a Lope, sobre todo cuando vio aparecer en 1628 la Primera parte de las comedias de Juan Ruiz de Alarcón, protegido del conde-duque. De eso se queja amargamente en su epistolario: «Las Comedias de Alarcón han salido impresas: solo para mí no hay licencia» ${ }^{8}$.

Así las cosas, cobra especial valor, por ejemplo, uno de los sonetos que únicamente conservamos en el códice Daza — en consecuencia, no muy difundido- y que lleva por título «La fábula»:

7 Estudia muy bien esta cuestión Moll (1974 y 2011); por lo que se refiere a la prosa, ha de completarse con Cayuela (1993).

8 La cita es de Vega (1989: Iv 131). 
Si en los cuidados de la vida humana alivio soy de tus mortales penas.

Si excusa para huir de las sirenas del mal de Amor la música profana. Si claro espejo a la prudencia cana, si dócil freno a las ardientes venas. ¿Por qué duro Anaxágoras condenas de mi (festiva) acción la risa urbana? No soy la que los vicios idolatro, que solo escrita soy para escarmiento. Sin leyes de las horas veinticuatro, docta enseñar y entretener intento ${ }^{9}$. Inhumano Catón (sal) del teatro, humano Cicerón escucha atento (fols. 100v-101r).

Creo que aquí el vocablo «fábula» guarda estrecha relación con el teatro. Nada tiene que ver con las fábulas esópicas y es más un término aristotélico, de su Poética. El verso «Inhumano Catón sal del teatro» no deja lugar a dudas. Con todo, lo que aquí interesa destacar es que el Fénix escribe un poema que puede considerarse —en plena suspensión de las licencias de impresión de comedias, es decir, en unos tiempos recios para la escena- una encendida defensa del arte dramático frente a los enemigos del teatro. Especialmente interesante me parece el verso «Inhumano Catón sal del teatro», que es toda una manifestación de una manera de entender la elaboración de una pieza dramática basada en el entretenimiento, en procurar divertir al público de los corrales.

En fin, esa percepción que tiene Lope, y que se agudiza en los últimos años de su vida, que consiste en pensar que la corte no ha sabido reconocerle sus méritos y, consecuentemente, el escritor ha tenido que entregarse a obras de entretenimiento para ganarse el pan, se sintetiza espléndidamente en estos versos del poema titulado «A Claudio»:

Hubiera sido yo de algún provecho,

si tuviera mecenas mi Fortuna;

mas fue tan importuna,

que gobernó mi pluma a mi despecho;

tanto, que sale (qué inmortal porfía)

cinco pliegos de mi vida el día (Vega, 2015: II 41) ${ }^{10}$.

Sea como fuere, y a pesar de lo que acabamos de leer, la verdad es que algunas de las mejores piezas dramáticas del Fénix pertenecen a esta última

\footnotetext{
9 Tachado debajo de este verso «enseñar deleitando toda intento».

${ }_{10}$ Oleza (2004) resume la cuestión de la falta de mecenazgo público en Lope.
} 
etapa de su vida: La noche de san Juan (1631), El castigo sin venganza (1631)11, Las bizarrías de Belisa $(1634)^{12}$, El Amor enamorado (representada en el Palacio del Buen Retiro el 31 de mayo de 1635). Es más, no sabemos el título de otras que se representaron con seguridad en esos años, muchas veces delante de la familia real y de la corte. No debe olvidarse, por otro lado, que también tomó parte con sus comedias en las frecuentes celebraciones religiosas que se llevaron a cabo en ese tiempo. A este respecto debe destacarse su pieza La vida de san Pedro Nolasco, comedia que Lope escribió en 1629 por encargo de la Orden de la Merced para celebrar en Madrid la canonización de su fundador ${ }^{13}$.

De esta manera no es cierto que Lope, aunque acaso quisiera hacerlo, dejara de escribir para el teatro, si bien es verdad que se encontró con algunos problemas que le hicieron más difícil el poder llegar con sus obras al público de los corrales y al Rey, según acabamos de ver en la carta arriba citada. Incluso cabe señalar que el llamado «ciclo de senectute», o la etapa del Lope último, puede considerarse como una de las épocas más fecundas y brillantes en lo que se refiere a la publicación de obras. Así, por ejemplo, lo atestigua Pedraza Jiménez (2003: 193):

[Lope de Vega] mantuvo su actividad literaria hasta el día que precedió a su muerte, el 27 de agosto de 1635. En los últimos años de su vida fue capaz de crear un puñado de obras maestras: El castigo sin venganza (1631), La Dorotea (1632), los poemas (escritos en su mayoría entre 1631 y 1633) que se incluirían en la edición póstuma de La vega del Parnaso (1637) y sus últimas y geniales Rimas de Tomé de Burguillos (1634), además de una decena de comedias estimables. Difícilmente se encontrarán cuatro años mejor aprovechados en la literatura universal.

Del mismo parecer es Profeti (1997: 12) cuando escribe que «la definición misma que se ha atribuido a su producción de estos años, "ciclo de senectute",

11 Pedraza Jiménez (2003: 196-197) recuerda que en 1631 se le encarga a Lope La noche de san Juan para la fiesta que organiza la condesa-duquesa de Olivares en el palacio del conde de Monterrey, con asistencia de los reyes. Más interesante es el caso de El castigo sin venganza. En el Prólogo que Lope incluye en la edición suelta de esta tragedia (Barcelona, 1634) se dice que se representó en la corte «sólo un día por causas que a v.m. le importan poco». El manuscrito autógrafo lleva fecha de 1 de agosto de 1631, la censura de la representación es de 9 de mayo de 1632, es decir, nueve meses después de su terminación; la única puesta en escena fue el 3 de febrero de 1633 y la prínceps de 1634 .

12 Lope cierra su comedia Las bizarrías de Belisa, acabada el 24 de mayo de 1634, con estos versos llenos de melancolía y tristeza: «Senado ilustre, el poeta | que ya las musas dejaba, | con deseos de serviros | volvió otra vez a llamarlas | para que no le olvidéis | y aquí la comedia acaba».

13 Véase Florit Durán (2008). Sobre la práctica dramática de Lope en estos años véanse Oleza (2003 y 2004), Iglesias Feijoo (2001) y González Cañal (2002). 
ha contribuido a pintar la silueta de un Lope amargado que intenta alejarse del mundo del teatro, o que se empeña en operaciones de revancha», para más adelante tratar en su trabajo de desmontar esa silueta lopesca.

Como han señalado los biógrafos de Lope, por estas fechas de las que se está hablando el Fénix pretendía un cargo real, el de cronista, que nunca llegó, y también disfrutar de la influencia de algún poderoso que, como el duque de Sessa, le amparase en sus continuos momentos de penuria. Sus intentos parece que resultaron vanos, salvo en el caso de este último noble, cuya cargo de secretario oficioso ocupó durante muchos años; pero tanto en sus cartas $^{14}$ como en las poesías de ese período encontramos el deseo de granjearse la voluntad de los poderosos para obtener alguna recompensa, de ahí el tono de varias poesías de aquellos tiempos, de algunas de las cuales ahora daré noticia. Y es que uno de los motivos recurrentes de este ciclo de senectute, tal como escribe Rozas (1990: 78), es justamente la búsqueda del mecenazgo. Ello convierte al Fénix en una especie de poeta cortesano, atento a alabar a los poderosos, empezando por el rey y la familia real, siguiendo por el conde-duque y su familia y prosiguiendo con nobles como el duque de Sessa (loa para la Égloga Antonia, del códice Durán), el de Feria (poema n. ${ }^{\circ} 13$, del mismo códice, donde se dirige «a los casamientos del Excelentísimo Señor duque de Feria» — se imprimió en 1627 en el libro Corona trágica-); el de Béjar (poema n. 34 del mismo códice -Don Francisco Diego López de Zúñiga Sotomayor, VII duque de Béjar (1619-1636)—); o eclesiásticos como el cardenal Barberino y su séquito (varios poemas en el códice Durán y dos más en el Pidal).

Permítaseme que empiece la serie encomiástica por su égloga elegíaca Amarilis. Antes quiero advertir que lo que me interesa examinar no son tanto los textos en sí mismos, puesto que todos ellos forman parte canónica del género encomiástico y ofrecen los rasgos propios de dicho género, sino la intrahistoria de los mismos, las circunstancias en las que fueron escritos, a quiénes iban destinados, con qué ocasión. Eso es de lo que quiero ocuparme en estas páginas.

El poema Amarilis se publica por primera vez en una edición suelta al cabo de unos meses de la muerte de Marta de Nevares (Amarilis, égloga, Ma-

14 Así, por ejemplo, le escribe al duque de Sessa hacia 1629-1630: «[quiero] suplicar a vuestra excelencia reciba con público nombre en su servicio un criado que ha más de veinticinco años que le tiene secreto; porque sin su favor no podré salir con vitoria de este cuidado, nombrándome, algún moderado salario, que, con la pensión que tengo, ayude a pasar esto poco que me puede quedar de vida. El oficio de capellán es muy a propósito. Diré todos los días misa a vuestra excelencia, y asistiré a lo que me mandare escribir o solicitar de su servicio y gusto. La dificultad no lo es, pues con pasarme de la merced al vos y escribirme en los libros, está vencida» (Vega, 1989: Iv 144). 
drid, por Francisco Martínez, 1633), aunque figura ya en el códice Daza ${ }^{15}$. Lo que deseo destacar ahora es que la obra está encabezada por unas palabras de Lope dedicadas «a la cristianísima reina de Francia», Ana de Austria, la hermana de Felipe IV; palabras que serían, y es un hecho significativo, eliminadas al incorporar esta égloga a La vega del Parnaso (1637). Este paratexto es importante pues entra de lleno en la órbita del mecenazgo; asunto que conviene analizar de forma tangente al ciclo de senectute, pues no en vano nuestro poeta dedica su égloga a una mujer que demostró estar siempre interesada por el arte y las letras. De hecho, Lope no quiso dedicarle sólo esta obra, sino que se propuso ofrecerle un proyecto que no vería la luz en vida del autor, el Parnaso, libro que sería retomado por sus herederos y que reformularían tanto por lo que se refiere a los contenidos como en el propio título: La vega del Parnaso. Felipe Pedraza, en su prólogo a la edición facsimilar del poema (Vega, 2010: 23), expone las razones que podrían haber llevado a Lope a abandonar este proyecto, destacando el hecho de que tal vez Ana de Austria no hubiera contestado a la dedicatoria de la propia égloga, algo que sin duda habría hecho desistir al poeta de conseguir su mecenazgo. Destaco de la dedicatoria lo siguiente:

Desde que fue vuestra majestad a Francia y, pasando el río que la divide de la España, dio tan justa materia de sentimiento a cuantos estábamos presentes a su partida, determiné dedicar a Vuestra Majestad algún escrito de mi humilde ingenio, pareciéndome que no cumplía con la obligación del amor que os deben por derecho divino y humano los españoles, de quien fuistes serenísima princesa, mientras no se dieron las manos la esperanza y la posesión del rey nuestro señor, que hoy obedecen y que Dios guarde, emperador del Nuevo Mundo y sucesor glorioso a Felipe el Grande y a la preciosa Margarita. Mas, ofreciéndose muchas dificultades, no he podido satisfacer a mi deseo el voto, y a vuestra majestad la deuda; que no hay tan rigurosa tormenta por la mar como las que corre por la tierra un hombre si la fortuna, con obstinado disfavor, le desampara. [...] Corona de la grandeza fue siempre la benignidad. ¿Quién será tan bárbaro que no la espere de vuestro divino valor? (Vega, 2010: 157-158).

Pedraza (Vega, 2015: II 657) apunta con acierto que el primer párrafo se remata con la queja de Lope por el reiterado desdén (obstinado favor) de los poderes públicos, que lo ha condenado a sufrir tan rigurosa tormenta y lo ha privado del tiempo necesario para escribir una obra en homenaje a la reina Ana de Austria (1601-1666), hija de Felipe III y mujer de Luis XIII.

Un par de años antes (abril-julio de 1631), Lope había escrito la Égloga panegírica al epigrama del serenísimo infante Carlos (Vega, 2015: I 325-361). Por

15 Marta de Nevares — Amarilis - muere la noche del 6 al 7 de abril de 1632. 
epigrama el Fénix se refiere al soneto « $\mathrm{O}$ h rompa ya el silencio el dolor mío...!», compuesto por el infante don Carlos (1607-1632), segundo hijo varón de Felipe III y Margarita de Austria, y hermano, como Ana de Austria, de Felipe IV. Lo que me interesa aquí resaltar es que considero que este poema y sus circunstancias son ejemplares en todo lo que guarda relación con las estrategias lopescas para acercarse al poder, ya que el dedicatario de este texto es el duque de Medina de las Torres, don Ramiro Felipe de Núñez Guzmán, quien en 1625 se casó con María de Guzmán ${ }^{16}$, hija del conde-duque de Olivares y, aunque enviudó año y medio después de su boda, don Gaspar — su suegro- siempre le protegió hasta el punto de que «era una de las personas más próximas a Felipe IV, de cuyo servicio y escolta se ocupaba» (Vega, 2015: I 336).

Los ochenta primeros versos de la composición se consagran a alabar hiperbólicamente a don Ramiro Felipe y a su linaje: la casa de Guzmán, una de cuyas ramificaciones fue el condado de Olivares. Véase el arranque del poema:

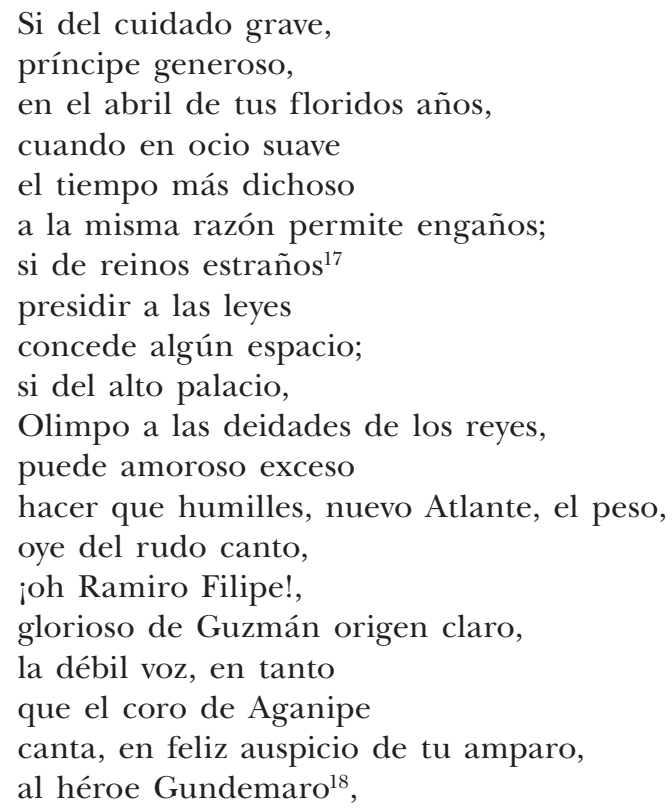

16 Lope le dedica a doña María el poema en octavas reales La rosa blanca, que aparece en La Circe (1624), obra que tiene como dedicatario al conde-duque de Olivares.

17 Es probable que aluda al cargo de canciller de Indias que el duque desempeñaba.

18 Gundemaro: apunta Pedraza (Vega, 2015: i 337) que se trata de una forma romanizada de un nombre germánico del que se supone que procede el de la familia Guzmán. Fue el de un rey de España, que accedió al trono tras el asesinato de Witerico en 609. 
y los claros varones

de los armiños blancos,

no germanos ni francos,

ni príncipes normandos y britones,

sino Guzmanes godos,

todos leones y españoles todos.

[...]

Virtud, que no Fortuna,

de aquel Olivo sacro ${ }^{19}$,

de quien fuiste ascendiente, y de quien eres

hijo, sobre la luna

coloca simulacro $^{20}$,

y tú de tanto sol rayos adquieres. (Vega, 2015: I 335-340).

De manera que en estos primeros versos de índole genealógica, Lope se emplea con fuerza en la tarea de incensar no solo al dedicatario, sino también al conde-duque, aprovechando el hecho de que uno y otro tienen un tronco común: la dilatada casa de Guzmán, cuyo antiguo origen leonés también pondera el Fénix. Y todo ello en una égloga pastoril, según se ha dicho, que tiene como propósito fundamental alabar un soneto compuesto por el infante don Carlos de Austria. Ahora bien, como Lope nunca da puntada sin hilo, aprovecha esta Égloga panegírica para insistir en una de las ideas fuerza de sus últimos años: la penosa y lamentable circunstancia de que la necesidad económica, provocada por la falta de mecenazgo, le obligue a vender sus piezas dramáticas en el mercado teatral, es decir, que no tenga más remedio que convertir en mercancía vendible los frutos de su ingenio:

Silvio. Llevé, como otras veces, descuidado, dos cabritillos a vender, escritos de blancas manchas en color dorado.

TIRsi. ¿Que un pastor como tú venda cabritos!

Silvio. Cuando salí del prado de la aldea, sus madres y ellos alternaban gritos; mas si fueran del pecho de Amaltea, con la necesidad, no respetara de Júpiter la cándida Lactea ${ }^{21}$.

19 Aquel Olivo sacro: manifiesta alusión a la casa de los condes de Olivares (una ramificación de los Guzmanes), con la que había emparentado don Ramiro al casarse con doña María de Guzmán.

20 Como bien señala Pedraza (Vega, 2015: I 340) estamos ante una versión cultista del dicho «subir a uno sobre el cuerno de la luna», es decir, «alabarle excesivamente».

21 Pedraza (Vega, 2015: I 334): «La necesidad económica de Lope le obliga a vender sus obras en el mercado teatral. Para ponderar el carácter imperioso e inevitable de estas operaciones, continúa con la metáfora de los "cabritos escritos": aunque fueran hijos de la mítica 
Nótese, y es en lo que quiero hacer hincapié, cómo — siempre que puedeLope trae a colación para elogiarlo, adularlo y para hacerle destinatario de sus peticiones al todopoderoso conde-duque de Olivares o a las personas que están en su órbita familiar, como hemos visto arriba. Según recuerda Carreira (2016: 445), «Lope de Vega anduvo muy alerta con el nuevo régimen desde el primer momento: al dedicar al valido El premio de la hermosura, comedia impresa el mismo año en que empezó su privanza (Parte XVI, Madrid, Viuda de Alonso Martín, 1621)». Recuérdese, asimismo, que Lope también le dedica, como ya quedó dicho arriba, La Circe (1624) al conde-duque y los Triunfos divinos (1625) a doña Inés de Zúñiga, condesa de Olivares. Como bien señala Núñez Rivera (2010: 177):

La razón íntima y última para tal dedicatoria [la de La Circe] acaso se encuentre en el anhelo de Lope por conseguir un puesto de cronista en la corte, una antigua aspiración no satisfecha, desde que concursara en 1611. En 1620 lo ha hecho de nuevo, aunque finalmente consiga la plaza Pellicer, su máximo rival dialéctico en el ciclo de senectute. En efecto, escritores más jóvenes y mejor relacionados debieron de dar al traste con las ilusiones del Fénix.

Al respecto de lo que se viene señalando aquí, resulta muy elocuente el soneto dirigido, precisamente, a don Gaspar de Guzmán. El poema, que figura en el códice Daza, y por lo tanto hay que situarlo en la última época de Lope, es muy poco conocido porque apenas se ha citado hasta ahora a pesar de su notable importancia. Ofrecemos, en nuestra opinión, la transcripción más correcta del manuscrito autógrafo de Lope, señalando en nota las lecturas, a nuestro juicio equivocadas, de Entrambasaguas:

Así la sucesión que sola os falta ${ }^{22}$ tantos Fenis de vos Guzmán reciba, que vos viváis por ella y ella viva sobre los siglos poderosa y alta.

Y sin hacer en sus progresos falta, vuestro esplendor corone sucesiva, como pimpollos ${ }^{23}$ de perpetua Oliva que el verde tronco ${ }^{24}$ generoso esmalta.

Que deis próspero fin a lo que os pido, pues en vuestra real naturaleza ni vive disfavor ni duerme olvido.

\footnotetext{
cabra Amaltea, que amamantó a Júpiter y cuya leche, según algunas versiones del mito, dio origen a la Vía Láctea, los hubiera vendido por necesidad».

22 Su hija María, la esposa de don Ramiro Felipe de Núñez Guzmán, murió sin descendencia.

23 Para «pimpollos» véase el poema A Claudio (Vega, 2015: II 45).

24 Entrambasaguas lee «turco».
} 
Vuestra Oliva ${ }^{25}$ es laurel de mi cabeza: no se diga en el mundo que ha vencido mi fortuna crüel vuestra grandeza. (fol. 124v) ${ }^{26}$.

Como se ve sin dificultad, el soneto se configura como una pieza laudatoria a favor de Olivares, al igual que otras muchas producciones del Siglo de Oro, relacionadas con el mecenazgo. Es en los dos tercetos donde Lope, tras la adulación de los cuartetos, coloca una súplica: que el conde-duque le ampare, proteja y favorezca, demanda espléndidamente sintetizada en el endecasílabo «Vuestra Oliva es laurel de mi cabeza», cuya lección original restituimos aquí.

Hemos hablado hasta el momento, entre otras composiciones, de la dedicatoria a doña Ana de Austria y de la Égloga panegírica a un soneto escrito por don Carlos de Austria. Pues bien, Lope también escribe un poema dedicado, en esta ocasión, al hermano menor de Felipe IV, y que lleva por título $A l$ serenísimo señor don Fernando de Austria, infante de España, cardenal de Roma, su protector, la Congregación de Sacerdotes Naturales de Madrid dedica esta canción. Por Lope Félix de Vega Carpio (Vega, 2015: i 363-390). Se trata de un poema de circunstancias que aspiraba a conseguir la protección del más joven de los hijos de Felipe III, el cardenal-infante don Fernando de Austria, para un instituto profesional y piadoso formado por los sacerdotes naturales y oriundos de Madrid a modo de montepío o sociedad de socorros mutuos. Se publica en La vega del Parnaso (1637) y su primera redacción la encontramos en el códice Pidal (fols. 60v-69r). Dicho códice incluye en el fol. 69v una suerte de colofón-dedicatoria al cardenal-infante que no se recogió en el impreso. Quiero ahora simplemente resaltar que Lope se dirige al cardenal-infante en el tono elevado de estos poemas laudatorios y encomiásticos que se están viendo (Vega, 2015: I 373-374):

Tú, sacro, serenísimo Fernando, alto honor de la púrpura de Roma, de nuestra duración feliz auspicio, que como joven sol iluminando la aurora, que de ti principio toma, ejerces, protector, tan regio oficio, recibe en sacrificio

25 Entrambasaguas lee «obra». La verde oliva y el laurel sagrado, además de ser plantas que podían formar parte del jardín de Lope, son símbolo de dos rasgos que el autor se atribuyó muchas veces a sí mismo: el carácter pacífico y la inspiración poética (Vega, 2015: II 112).

26 «Soneto dedicado a don Gaspar de Guzmán, conde-duque de Olivares, que debió de acompañar a alguna petición del Fénix, al poderoso valido de Felipe IV, que ignoro, por ahora, cuál sería, si bien es casi seguro que, como en tiempos anteriores, nada conseguiría el poeta» (Entrambasaguas, 1970: 93). 
—si nacen de las almas los mayoresesta - aunque humilde ofrenda, del esperado fruto imagen- prenda, como el altar las primitivas flores; y escucha atento, de tu luz infusas —-sacerdotisas ya-, las dulces Musas, que en mayor ocasión para tu gloria, destinan versos a inmortal memoria.

En esa táctica desplegada por el último Lope para tratar de obtener la atención y el favor de los poderosos, sobre todo de Felipe IV y del condeduque de Olivares, cobran sustancial relevancia dos composiciones: los Versos a la primera fiesta del palacio nuevo (Vega, 2015: i 537-563) y el soneto «Desprecia invicto y formidable espanta», recogido en el volumen cuidado por el cronista de los Reinos de Castilla y León don José Pellicer de Tovar, y que lleva por título Anfiteatro de Felipe el Grande (Madrid, Juan González, 1631). Me ocupo primero del soneto, y también de algún aspecto del libro donde aparece dicho poema, ya que fue redactado antes que los versos para celebrar la apertura del nuevo Palacio del Buen Retiro. El poema tuvo que ser escrito en el periodo que va del 13 de octubre (día del espectáculo de fieras en el parque de Palacio) al 3 de noviembre (fecha de la censura eclesiástica a cargo de Jerónimo de Villaizán) de 1631. Por cierto, el manuscrito del poema, que está en el códice Daza (fols. 22v-26r), es un precioso ejemplo de cómo en ocasiones Lope para escribir un texto poético —en el caso que nos ocupa fueron catorce versos- hubo de emborronar varios folios. Esta vez, tres y medio.

Como quedó dicho, el 13 de octubre de 1631, en el trascurso de una fiesta preparada por el conde-duque de Olivares, el rey, desde el balcón de una panadería de la plaza del Parque (ya que la Plaza Mayor estaba en obras), donde se celebraba el festejo, dio muerte, disparándole con un arcabuz, al bravísimo toro que había vencido sobre los demás animales. De inmediato, Pellicer de Tovar reúne una junta de poemas de varios autores consagrada a celebrar tamaña empresa. La nómina es apabullante: Lope de Vega, González de Salas, Francisco de Rioja, Quevedo, Luis Ulloa de Pereira, Juan de Jáuregui, Calderón, Valdivielso, el Príncipe de Esquilache, Hurtado de Mendoza, Gabriel Bocángel, Ruiz de Alarcón, Luis Vélez de Guevara, Antonio de Solís, Rojas Zorrilla, Saavedra Fajardo, Pérez de Montalbán, Mira de Amescua..., hasta formar un libro compuesto por ochenta y seis sonetos, diez espinelas, tres romances, una silva y unas estancias ${ }^{27}$.

27 Nótese que en la nómina figuran algunos dramaturgos que Lope calificó de «pájaros nuevos» en su poema Amarilis: Calderón, Rojas, Hurtado de Mendoza, entre otros (González Cañal, 2002: 153). 
En fin, más allá del soneto de Lope, que ahora citaré, me interesan dos cosas. La primera tiene que ver con el hecho de que en la portada se nos dice que el libro se publica «con la protección del Excelentísimo Señor Don Gaspar de Guzmán, Conde, Duque y Gran Canciller» ya que, obviamente, el dedicatario de la obra es el propio monarca Felipe IV, no Olivares. En los preliminares Pellicer de Tovar (1631) incluye unas palabras suyas destinadas a don Gaspar de Guzmán en las que, entre otras cosas, dice lo siguiente:

He querido ofrecer estos elogios al Rey Nuestro Señor, llevando la protección de V.E., para que con tal amparo sean mejor admitidos pues, empeñado su nombre de V.E. en ellos, es fuerza que tengan buena fortuna y que yo quede confiado de haberlos sabido dar tan alto puesto como tendrán por su mecenas y protector.

Estamos, pues, ante un nuevo caso en el que un escritor señala la condición de mecenas y de protector de las artes que se le atribuye en esa época ya a Olivares, más allá del hecho de que lo que ahora tenga que proteger y amparar sea un conjunto de poemas encomiásticos.

Con todo, Lope no solo participa con un soneto en este libro cargado hasta la náusea de mitificación, pleitesía, lisonjas, halagos y alabanzas a Felipe IV (Díez de Revenga, 1988 y García Bernal, 2011), perfecto ejemplo del arte de la laudatio y la apología de un monarca, al que los poetas, tal y como recuerda García Bernal (2011: 82), «tributan sus composiciones hasta tejer un tupido tapiz mitológico que exalta la figura de Felipe el Grande como el Júpiter español».

Un libro, insistimos, puesto bajo el amparo y la protección del condeduque. Solamente con el soneto estaríamos ya ante un nuevo y valioso ejemplo de la estrategia lopesca de la que estamos hablando, es decir, del sostenido empeño del Fénix por aparecer entre el número de los elegidos y favorecidos por las esferas del poder. No se olvide que nos situamos a finales de 1631, es decir, en la etapa ya del desengaño del poeta, ni tampoco descuidemos las constantes quejas de Lope, tanto en sus cartas como en varios textos literarios, motivadas por lo que él juzga una falta de reconocimiento de su persona y obra por parte de los poderosos de cuya protección se considera sobradamente merecedor. Pues bien, y es algo que no suele decirse ni traerse a colación, el autor de la censura civil del Anfiteatro de Felipe el Grande es frey Lope Félix de Vega Carpio, del hábito de San Juan:

Esta acción de Su Majestad que trasladó su singular destreza del campo al anfiteatro y del monte solo al espectáculo universal sin que se debiese tan peregrino suceso a la Fortuna por accidente, sino a la ciencia por ejercicio, y a la gracia que el cielo para toda obra militar heroica ha dotado su real 
naturaleza, he visto por mandado y comisión de V.A. ${ }^{28}$ escrita en diversos epigramas de los mejores ingenios españoles que profesan estos estudios. No tiene objeción divina ni humana en todo su discurso ni el que tan doctamente ha hecho don José Pellicer de Tovar, a quien se debe que la gocen y vean celebrada con tanta elegancia y erudición los que no la vieron ejecutada con tan airosa destreza y gracia. Puede V.A., siendo servido, permitir que se imprima para que vean también otras naciones qué amor tienen a su rey sus vasallos y qué bizarra disposición su heroico príncipe... (Pellicer de Tovar, 1631).

Si en esta censura Lope hace hincapié en la destreza venatoria del monarca, en su ardor guerrero y en el amor que le tienen sus vasallos, es decir, si pondera su poder militar y político, en el soneto que escribió para celebrar la hazaña nos situamos ya directamente en la imagen mítica del rey sol (rey planeta) como método de alabanza (Vélez Sáinz, 2017). Como es sabido, en el sistema tolemaico, este astro constituía el cuarto de los planetas que se suponía giraban en torno a la tierra. La coincidencia del ordinal con el del rey Felipe determinó que la adulación cortesana los identificara (Vega, 2015: I 542). Así dice el soneto:

Desprecia invicto y formidable espanta selvas de fieras, animoso toro, encrespa la cerviz al cerco de oro, y con el bruto imperio se levanta.

Cuando el Planeta, cuya sacra planta besan dos mundos, con marcial decoro tan breve rayo disparó sonoro, que ardiendo el toro al tiro se adelanta.

¡Oh fiera victoriosa!, preferida al oso, al tigre y al león, tan fuerte que de sola deidad fueras vencida.

28 Se trata de la aprobación civil, elemento legal que, como la censura eclesiástica, formaba parte de los preliminares de toda obra impresa y era el paso previo para la concesión de la licencia para la impresión del libro. El V.A. a quien se dirige el censor Lope de Vega no es otro que el Consejo Real de Justicia y Gobierno o de Castilla, instancia suprema en todo lo que tenía que ver con el gobierno, la administración y la justicia del Reino de Castilla y, por lo que ahora nos interesa, autoridad máxima, desde la pragmática de 1558, en lo relacionado con la impresión de libros y que tenía el tratamiento de «Vuestra Alteza». Dicho Consejo era, pues, quien designaba la persona o las personas encargadas de la censura de la obra para cuyo examen se les presentaba. Lo cierto es que en la elección de los miembros no existía una norma fija, sino una gran libertad, aunque se procuraba buscar personas doctas en la materia del libro que había de censurarse. El caso es que Lope de Vega, como Tirso, Quevedo, Calderón, Salas Barbadillo, Jáuregui y otros muchos escritores auriseculares, ejercieron de censores civiles. Zamora Lucas (1941) analiza el papel de Lope de Vega en tanto que censor de libros. 
Dichosa y desdichada fue tu suerte, pues como no te dio razón la vida, no sabes lo que debes a tu muerte (Pellicer de Tovar, 1631: 16v).

Según recuerda Vélez Sainz (2017: 56-57) fue el propio Lope el primero en emplear la fórmula «rey planeta» dedicada a un Austria; en concreto, en unas letrillas con motivo de la muerte del príncipe Carlos, hijo de Felipe II: «Aquí dio fin un cometa | que del mismo sol nació, | con resplandor que mostró | ser hijo de tal planeta».

No obstante, lo significativo, a mi modo de ver, es el hecho de la doble presencia de Lope en una obra cuyo responsable es José Pellicer de Tovar, el cronista real —puesto al que había aspirado el Fénix en 1611, 1620 y 1629; y también al que siempre se le ha considerado su enemigo (Rozas, 1990: 133-168)—, en un libro que está todo él consagrado a la alabanza de Felipe IV y que está puesto bajo la protección de Olivares. Dicho de otro modo: ante ejemplos tan significativos y valiosos como este, ¿no habría que tomarse las sostenidas lamentaciones lopescas, casi jeremíacas, con mayor prevención? Porque aquí no parece que las esferas del poder, perfectamente representadas en el monarca, en su valido y en su cronista, hayan orillado, despreciado o ninguneado al escritor madrileño. Todo lo contrario ${ }^{29}$.

Es que además un año antes el Fénix había escrito en su Laurel de Apolo (1630) —libro, por cierto, dedicado a don Juan Alfonso Enríquez de Cabrera, almirante de Castilla - lo siguiente sobre el cronista real:

Ya don Jusepe Pellicer de Salas

con cinco lustros solos sube al monte;

ya, nuevo Anacreonte,

fénix extiende las doradas alas

que el sol inmortalice,

y pues él mismo dice

que tantas lenguas sabe,

busque entre tantas una que le alabe.

Como muy bien señala González Cañal (2002: 142), «no le hizo gracia al joven cronista esta pulla de Lope y arremetió con dureza contra el anciano sacerdote en el prólogo de sus Lecciones solemnes..., publicadas el mismo año».

${ }^{29}$ El soneto de Lope ocupa la posición octava en el libro. Antes de Lope figuran cinco nobles [el príncipe de Esquilache (Francisco de Borja y Aragón. De 1615 a 1621 fue virrey del Perú), el marqués de Alcañizas, el conde de Coruña, el marqués de Javalquinto (con dos poemas) y el vizconde de Tovar] y Antonio Hurtado de Mendoza, secretario real. Es decir, Lope aparece en la antología antes de que lo hagan Quevedo, Calderón, Rioja, Solís, Pérez de Montalbán, Saavedra Fajardo, etc. 
Sin embargo, ante lo que se acaba de ver más arriba ¿es posible admitir sin más que Pellicer y Lope en esos años son de verdad enemigos encarnizados? ¿No convendría matizar un poco lo que hasta ahora se ha repetido por parte de la crítica con respecto a las relaciones entre el joven Pellicer y el anciano Lope?

Por esta razón también se han de tener en cuenta los Versos a la primera fiesta del palacio nuevo, así como las circunstancias de su redacción. No solo porque Lope vuelva a utilizar la misma fórmula que acabamos de ver y despliegue una serie de apelativos atañederos a la condición del rey planeta de Felipe IV («llamó los ojos donde el sol salía, | y en la arena marcial de la palestra, |Júpiter español los rayos muestra»; «Donde Felipe es sol, seré Faetonte»; «nuestro divino Febo»), sino también porque el Fénix es invitado a participar, una vez más, en un acto encomiástico destinado, en esta ocasión, a celebrar la apertura del nuevo Palacio del Buen Retiro en 1633. Recuérdense los hechos: el primero de diciembre de 1633 el condeduque de Olivares les entrega a los reyes Felipe IV e Isabel de Borbón las llaves de su nueva residencia. En el proyecto y en el desarrollo de las obras tuvo una participación constante el valido como tuvo, asimismo, un protagonismo absoluto en la organización de la fiesta inaugural, festejos que duraron seis días y que conocemos con detalle gracias a las referencias de León Pinelo en sus Anales de la villa de Madrid, a los informes de las embajadas de Florencia, Inglaterra y Venecia, y a un impreso titulado Copiosa relación de las grandiosas fiestas que la católica majestad del rey nuestro señor mandó hacer en la villa de Madrid [...] a honra del palacio y plaza nueva, lunes cinco de diciembre de este presente año de 1633 (Sevilla, Juan Gómez de Blas, 1633).

Dentro del sistema propagandístico que siempre utilizó don Gaspar de Guzmán y su camarilla, el siguiente paso, una vez inaugurada la nueva residencia de los reyes, consistía en difundir el hecho a través de una campaña de promoción de los festejos para mayor gloria del monarca y del propio valido. Pedraza (Vega, 2015: i 541) sostiene que, precisamente, dentro de la campaña «tuvo que figurar el encargo a Lope de un poema celebrativo del nuevo edificio y de propaganda del proyecto político que encarnaba». Y así fue. Lope escribió, presumiblemente en el mismo mes de diciembre de 1633, un poema de 276 versos, vertebrado en 46 liras de seis versos, y titulado, como quedó dicho arriba, Versos a la primera fiesta del palacio nиеvo. En el mismo aparece Felipe IV citado veintiséis veces: una como monarca y Felipe; dos como majestad, tres como rey de España, Júpiter y león, y en las demás ocasiones como real planeta, Febo y, sobre todo, sol (Vega, 2015: i 542-543). Más interesante, a mi modo de ver, es el hecho de que, además del rey, los únicos aludidos en el poema sean la reina Isabel 
de Borbón, el príncipe Baltasar Carlos y el valido Olivares, de quien dice lo que sigue:

Iba a su lado el conde, que méritos y amor igualan tanto, porque llegar adonde

a la misma Fortuna causa espanto, es virtud, es valor; que no hay estrella

de más felicidad que merecella.

Acción en que, prudente,

con tu respeto mismo te aconsejas.

Corrieron finalmente

la majestad y la virtud parejas,

si bien la diferencia prevenía:

que así corren también el sol y el día (Vega, 2015: i 551-552).

Nótese cómo Lope quiere subrayar en estos versos la estrecha relación entre el monarca y su valido.

De manera que, si juntamos la importante presencia de Lope en el Anfiteatro de Felipe el Grande con las circunstancias que rodearon la génesis de los Versos a la primera fiesta del palacio nuevo, nos encontramos con que tanto en 1631 como en 1633 nuestro poeta no puede lamentarse ni quejarse de desafecto por parte del más estrecho y cercano círculo de poder de Felipe IV. No se nos oculta que Lope interiorizó hacia el final de su vida la idea de que no había alcanzado ni el favor ni el premio que su ingenio merecía, es decir, no había podido obtener el patronazgo regio; pero no es menos verdad que en no pocas ocasiones, ya fuera por el despliegue de su estrategia literaria para tratar de acercarse al poder o porque realmente las esferas del poder lo acogieran de buen grado a él, vemos cómo el Fénix intervino activamente en el programa de propaganda diseñado por el propio Olivares y por su camarilla; y lo hizo porque se lo pidieron, porque contaron con él, porque se lo encargaron. Estamos ante unas circunstancias parecidas sobre las que llamó la atención Profeti (1997) cuando nos mostró con notable acierto que el teatro de Lope no fue tan olvidado en Palacio como se pensaba habitualmente, y sobre las que ha regresado con la perspicacia que le caracteriza Ferrer Valls (2017) al estudiar un grupo de obras de Lope representadas en el marco de una fiesta cortesana.

Lo apuntado, claro está, no contradice el hecho de que hasta el final de sus días Lope sintiera, por un lado, pena, dolor, pesadumbre, desengaño y rabia por lo que él creía que era cierto: la ingratitud de los poderosos hacia su persona y, por otro, que deseara desahogarse ante lo que él juzgaba como fallidos intentos por congraciarse con la familia real y con los gobernantes. De ahí que quiera traer hacia el cierre de este artículo un lema latino: Virtute 
perfecta non fit condignus honor («No hay honor suficientemente digno para premiar la perfecta virtud») ${ }^{30}$. El aforismo lo puso Lope al frente de uno de los últimos poemas que redactó, el que lleva por título Pira sacra en la muerte del excelentísimo señor don Gonzalo Fernández de Córdoba Cardona y Aragón (Vega, 2015: iII 553-594). La composición está dedicada al hermano del fallecido, que no es otro que don Luis Fernández de Córdoba, el VI duque de Sessa y mecenas de nuestro escritor. Tuvo que ser escrita entre el 16 de febrero de 1635 (muerte de don Gonzalo) y el 27 de agosto del mismo año (fallecimiento de Lope). Lo valioso, a mi modo de ver, es que en el poema se ofrece «el retrato de un noble caballero que siempre antepuso el bien de su patria y su rey a toda ambición personal» (Vega, 2015: III 557) y que, significativamente, vivió momentos de amargura e infortunio en su carrera política y militar por la falta de apoyo del rey y de Olivares ${ }^{31}$. Aunque de esto, obviamente, no habla Lope en el poema, pero era algo bien conocido por todos. Estamos, pues, ante un poema más que entraría en la serie lírica reivindicativa que Lope llevó a cabo entre 1632 y 1635 y cuyas dos mejores muestras serían, en nuestra opinión, A Claudio y Huerto deshecho, poemas bien conocidos, admirables y ejemplares de todo lo que fueron las circunstancias biográficas y literarias del último Lope.

\section{Bibliografía}

Carreira, A. (2016): «El conde-duque de Olivares y los poetas de su tiempo». Nueva Revista de Filología Hispánica, Lxiv.2, págs. 439-456.

Cayuela, A. (1993): «La prosa de ficción entre 1625 y 1634. Balance de diez años sin licencias para imprimir novelas en los Reinos de Castilla». Mélanges de la Casa de Velázquez, xxix.2, págs. 51-76.

Crivellari, D. (2015): «El trabajo del autor sobre sí mismo: Lope de Vega escribe La nueva victoria de don Gonzalo de Córdoba». Anuario Calderoniano, 8, págs. 93-111.

Díez de Revenga, F.J. (1988): «Monarquía y mito en la España del Siglo de Oro: el Anfiteatro de Felipe el Grande». En Ruiz Ramón, F. y Oliva, C. (coords.): El mito en el teatro clásico español. Madrid, Taurus, págs. 196-202.

Entrambasaguas, J. (1970): «Un códice de Lope de Vega autógrafo y desconocido». Revista de literatura, 75-76, págs. 5-117.

Ferrer Valls, T. (2012): «Lope y la creación de héroes contemporáneos: La nueva victoria de don Gonzalo de Córdoba y La nueva victoria del marqués de Santa Cruz». Anuario Lope de Vega, XviII, págs. 40-62.

\footnotetext{
${ }^{30}$ Es versión latina de un pasaje del libro cuarto de la Ética nicomaquea de Aristóteles.

31 Téngase presente que Lope escribió una comedia titulada La nueva victoria de don Gonzalo de Córdoba (1622), en la que el Fénix ensalza a don Gonzalo por haber llevado a la victoria a las tropas españolas contra las de los protestantes en la batalla de Fleurus, ocurrida el 29 de agosto de 1622 (Ferrer Valls, 2012 y Crivellari, 2015).
} 
— (2017): «Hablando con el rey: Lope de Vega en escena». Bulletin hispanique, 119.1, págs. 143-157.

Florit Durán, F. (1986): Tirso de Molina ante la comedia nueva. Aproximación a una poética. Madrid, Estudios.

- (2008): «Una comedia por encargo: La vida de san Pedro Nolasco (1629) de Lope de Vega». En Pedraza, F.B. y García González, A. (eds.): La comedia de santos. Almagro, Universidad de Castilla-La Mancha-Casa de Velázquez, págs. 201-217.

García Bernal, J.J. (2011): «De "Felipe el Grande” al "Rey pacífico”. Discursos festivos y funerales durante el reinado de Felipe IV». Obradoiro de Historia Moderna, 20, págs. 73-104.

García Reidy, A. (2013): Las musas rameras. Oficio dramático y conciencia profesional en Lope de Vega, Madrid-Frankfurt, Iberoamericana-Vervuert.

González Cañal, R. (2002): «Lope, la corte y los "pájaros nuevos”». Anuario Lope de Vega, 8, págs. 139-162.

Iglesias Feijoo, L. (2001): «Sobre la fecha de una comedia de Lope y su guerra con Pellicer». En Prosa y poesía. Homenaje a Gonzalo Sobejano. Madrid, Gredos, págs. 171-187.

Moll, J. (1974): «Diez años sin licencias para imprimir comedias y novelas en los reinos de Castilla. 1625-1634». Boletín de la Real Academia Española, 54, págs. 97-103.

- (2011): Problemas bibliográficos del libro del Siglo de Oro. Madrid, Arco Libros.

Núñez Rivera, V. (2010): Poesía y Biblia en el Siglo de Oro. Estudios sobre los «Salmos» y el «Cantar de los Cantares». Madrid, Iberoamericana.

Oleza, J. (2003): «El Lope de los últimos años y la materia palatina». Criticón, 87-89, págs. 603-620.

- (2004): «Las opciones dramáticas de la senectud de Lope». En Díez Borque, J.M. y Alcalá Zamora, J. (coords.): Proyección y significados del teatro clásico español. Madrid, seacex, págs. 257-276.

Pedraza Jiménez, F.B. (1978): «El desengaño barroco en las Rimas de Tomé de Burguillos». Anuario de Filología, Iv, págs. 391-418.

- (2003): El universo poético de Lope de Vega. Madrid, Laberinto.

- (2008a): Lope de Vega, genio y figura. Granada, Universidad de Granada.

- (2008b): Lope de Vega. Vida y literatura. Valladolid, Universidad de Valladolid.

Pellicer de Tovar, J. (1631): Anfiteatro de Felipe el Grande. Cieza, Antonio Pérez Gómez (reproducción facsímil, 1974).

Pérez de Montalbán, J. (2001): Fama póstuma a la vida y muerte del doctor frey Lope Félix de Vega Carpio y elogios panegíricos a la inmortalidad de su nombre. E. Di Pastena (ed.). Pisa, Edizioni ETS.

Profeti, M.G. (1997): «El último Lope». En Pedraza Jiménez, F.B. y González Cañal, R. (eds.): La década de oro en la comedia española: 1630-1640. Almagro, Universidad de Castilla-La Mancha, págs. 11-39.

Rennert, H.A. y Castro, A. (1969): Vida de Lope de Vega (1562-1635). Salamanca, Anaya (2. ${ }^{a}$ ed. con notas adicionales de F. Lázaro Carreter; $1 .^{a}$ ed. Madrid, Suce- 
sores de Hernando, 1919, procede de Rennert, The Life of Lope de Vega (1562-1635), Glasgow University Press, 1904).

Rozas, J.M. (1990): «Lope de Vega y Felipe IV en el "ciclo de senectute”. En Rozas, J.M.: Estudios sobre Lope de Vega. J. Cañas Murillo (ed.). Madrid, Cátedra, págs. 73-131.

SÁnchez Jiménez, A. (2018): Lope: El verso y la vida. Madrid, Cátedra.

Vega, L. de (1631-1634): Obras de Lope de Vega: Códice Daza. Biblioteca Digital Hispánica (en línea: <http://bdh.bne.es/bnesearch/detalle/bdh0000140452> [consulta: 29 de enero de 2019]).

- (1989): Epistolario de Lope de Vega. A.G. de Amezúa (ed.). Madrid, RAE, 4 vols. (edición facsímil de la de Madrid, Aldus, 1935-1943).

- (2010): Amarilis. Égloga. F.B. Pedraza Jiménez (ed.). Madrid, Fundación Caja Castilla-La Mancha-Universidad de Castilla-La Mancha-Universidad de Navarra.

- (2011): Códice Durán-Masaveu. Cuaderno autógrafo. V. García de la Concha y A. Madroñal Durán (eds.). Madrid, RAE-Fundación María Cristina Masaveu Peterson.

- (2015): La vega del Parnaso. F.B. Pedraza Jiménez (dir. ed.). Cuenca, Universidad de Castilla-La Mancha, 3 vols.

VÉlez SAInz, J. (2017): «El rey planeta»: suerte y divisa en el entramado encomiástico en torno a Felipe IV. Madrid, Iberoamericana.

Zamora Lucas, F. (1941): Lope de Vega, censor de libros. Larache, Artes Gráficas Biosca. 